\title{
Endoscopic endonasal approach for craniopharyngioma: the importance of the relationship between pituitary stalk and tumor
}

\author{
Yun-Sik Dho, MD, ${ }^{1}$ Yong Hwy Kim, MD, ${ }^{1}$ Young-Bem Se, MD, ${ }^{1}$ Doo Hee Han, MD, PhD, ${ }^{2}$ \\ Jung Hee Kim, MD, ${ }^{3}$ Chul-Kee Park, MD, PhD, ${ }^{1}$ Kyu-Chang Wang, MD, PhD, ${ }^{1}$ and \\ Dong Gyu Kim, MD, PhD'
}

Departments ${ }^{1}$ Neurosurgery and ${ }^{2}$ Otorhinolaryngology, Seoul National University College of Medicine, Seoul National University Hospital; and ${ }^{3}$ Division of Endocrinology and Metabolism, Department of Internal Medicine, Seoul National University Hospital, Seoul, Republic of Korea

OBJECTIVE The endoscopic endonasal approach (EEA) is commonly used for the treatment of craniopharyngioma; therefore, it is essential to analyze outcomes in order to understand the benefits and drawbacks. The goal of this paper was to evaluate the clinical features and outcomes associated with this treatment approach.

METHODS From July 2010 to March 2016, 82 adult craniopharyngioma patients underwent an EEA at the authors' institution. Of these cases, intraoperative records and immediate postoperative MR images were available for 68 patients. The patients underwent systemized endocrinological evaluation. Eighteen of 68 patients who underwent EEA for recurrence or regrowth of residual lesions after previous surgical management were excluded in the analysis of the anatomical tumor classification. The authors retrospectively analyzed preoperative clinical features and previous anatomical classifications, focusing on the relationship of the pituitary stalk and tumor, to determine predictive factors for the clinical outcome, such as the extent of resection, visual function, endocrinological function, recurrence rate, and complications.

RESULTS The mean tumor size was $2.5 \mathrm{~cm}$ ( $3.1 \mathrm{~cm}$ for primary tumors and $1.9 \mathrm{~cm}$ for recurrent lesions). Gross-total resection (GTR) was achieved in $62(91.1 \%$ ) patients (48 [96.0\%] patients with primary tumors and $14[77.8 \%]$ patients with recurrent tumors). The rate of GTR was higher in the primary group than in the group with recurrence $(p=0.038)$. The overall pre- and postoperative visual impairment scale (VIS) scores were 40.8 and 22.1, respectively (50.9 and 14.3 in the primary group and 30.7 and 29.9 in patients with recurrence, respectively). The improvement rate in VIS score was higher in the primary group than in the recurrent group $(p=0.001)$. Endocrinological function was improved in 4 patients $(5.9 \%)$ and deteriorated in 32 of 68 patients $(47.1 \%)$. Tumor invasion into the center of the pituitary stalk affected the postoperative outcomes most significantly. Cognitive dysfunction was observed in 22 patients before surgery and improved in 20 patients $(90.9 \%)$ after surgery. Hydrocephalus was found in 7 patients and resolved after surgery in all cases. CSF leakage occurred in $2(2.9 \%)$ of 68 patients and was repaired by revision surgery in both patients. Ten patients without CSF leakage also received antibiotics for the treatment of meningitis. The infection rate was higher in the recurrent group. Postoperative endocrinological evaluation showed no deficits in 12 patients and panhypopituitarism in 55 patients. The remaining patient had growth hormone deficiency. Forty-three patients had new-onset diabetes insipidus, and 1 patient had persistent diabetes insipidus after surgery. There were $2(2.9 \%)$ cases of recurrence during the mean 30.7-month follow-up period; one patient underwent radiosurgery and the other underwent reoperation.

CONCLUSIONS The EEA resulted in excellent surgical outcomes and acceptable morbidity rates, regardless of the anatomical location of the tumor. Invasion of the craniopharyngioma into the center of the pituitary stalk has strong predictive power for postoperative endocrinological outcome.

https://thejns.org/doi/abs/10.3171/2017.4.JNS162143

KEY WORDS craniopharyngioma; location; endoscopy; outcome; invasion; stalk; pituitary surgery

ABBREVIATIONS BMI = body mass index; EEA = endoscopic endonasal approach; GH = growth hormone; GTR = gross-total resection; ICA = internal carotid artery; STR = subtotal resection; VIS = visual impairment scale.

SUBMITTED August 17, 2016. ACCEPTED April 4, 2017.

INCLUDE WHEN CITING Published online September 29, 2017; DOI: 10.3171/2017.4.JNS162143. 
$\mathrm{C}$ RANIOPHARYNGIOMAS, thought to originate from embryonic squamous epithelial remnants of Rathke's pouch, account for $2 \%-5 \%$ of all central nervous system tumors. ${ }^{10}$ Craniopharyngiomas are not benign and are classified as WHO Grade I tumors. Their tendency to recur and the higher risk of reoperation has forced neurosurgeons to radically remove these tumors. However, total resection is not always possible because of tumor adhesion to adjacent neurovascular structures. Therefore, understanding the surgical anatomy and choosing the best approach for maximal surgical exposure are essential to attaining complete tumor removal with minimal postoperative morbidity. The anatomical locations and extent of craniopharyngiomas play critical roles in planning the surgical approach, and several classifications have previously been introduced to assist in determining the surgical approach. ${ }^{21,29,30}$ The original classification was based on the tumor's location in relation to the optic chiasm. Recent advances in the endoscopic endonasal approach (EEA), which achieves access through the planum and tuberculum sellae, have led us to extend its application to retrochiasmatic tumors. ${ }^{7}$ Kassam et al. ${ }^{14}$ established another classification scheme to identify the relationship between the infundibulum and craniopharyngioma, with other authors reporting favorable results after EEA. ${ }^{1,2,8,17,18}$ The purpose of this study was to evaluate the usefulness of these previous anatomical classifications for predicting clinical outcome after surgery and to determine the factors influencing postoperative clinical outcome after EEA. We analyzed the clinical outcomes and describe the specific features based on these outcomes. We categorized craniopharyngiomas according to their spatial and anatomical relationships with the pituitary stalk, optic chiasm, diaphragma sellae, and infundibulum, as suggested by previous studies, and we analyzed the surgical outcome of EEA.

\section{Methods}

After receiving approval from the institutional review board, we retrospectively reviewed the electronic medical records and imaging data of patients who underwent endoscopic endonasal resection of craniopharyngiomas. Between July 2010 and March 2016, 90 adult patients underwent surgery at our institution, of whom 82 (91\%) underwent an EEA. The EEA was recommended for patients with tumors located between the bilateral internal carotid artery (ICA) bifurcations and optic canals. Tumors that extended into the posterior fossa were also surgically treated with the simultaneous transtuberculum and transclival approach if they were between the bilateral ICAs in the clival region. Sixty-eight patients who had available intraoperative records, immediately postoperative MR images $(<48$ hours), and regular endocrinological evaluation records were included in this study. Endocrinological evaluation was performed as follows: endocrinological medications were administered in the outpatient clinic without stimulation tests in cases of pituitary stalk resection or obvious hypopituitarism, and the combined pituitary function test was conducted within 6 months after surgery only in patients without clinical hypopituitarism.
Sixty-eight consecutive adult patients (34 men and 34 women; mean age 50 years, age range 15-74 years) with craniopharyngiomas underwent EEA procedures at our institution. The EEA was the initial surgical intervention for 50 patients, and the remaining 18 patients had previously undergone surgery. The mean follow-up duration was 30.7 months. In the classification of craniopharyngiomas according to spatial and anatomical features, we excluded the 18 patients undergoing reoperation for recurrence or regrowth of residual lesions because the normal arachnoid membranes of the cisterns had been destroyed during the initial operation, thus changing the anatomical relationship of the pituitary stalk to the diaphragma sellae. These patients constituted the recurrent group in this study.

Clinical data encompassing the extent of resection, stalk preservation, endocrinological and neuroophthalmological outcomes, and postoperative complications were interpreted based on spatial and anatomical classifications. The tumor growth patterns were classified as prechiasmatic or retrochiasmatic based on midline sagittal MRI and intraoperative findings. ${ }^{30}$ The relationship between the tumor and the diaphragma sellae was determined during intraoperative dissection of the diaphragma from the tumor. The tumor growth pattern was correlated with the spatial relationship of the tumor to the diaphragma sellae and the competency of the aperture. Moreover, the anatomical relationship between the tumor and pituitary stalk was observed on midline sagittal MR images, and it was classified as preinfundibular, transinfundibular, or retroinfundibular. ${ }^{14}$ We also confirmed whether there was tumor invasion into the center of the pituitary stalk based on intraoperative findings. ${ }^{14,30}$

Tumor size was determined by the maximal tumor diameter based on MR images. The extent of tumor resection was confirmed by intraoperative findings and postoperative MR images acquired within 48 hours after surgery. Gross-total resection (GTR) was deemed as the absence of residual tumor by these criteria, and cases in which there was any small residual tumor were classified as subtotal resection (STR). We describe the patient clinical presentations and results of the preoperative evaluation in Table 1.

All patients underwent neuroophthalmological evaluation, including uncorrected visual acuity and Goldmann perimetry testing, preoperatively and within 6 months postoperatively. The extent of visual disturbance was analyzed according to the guidelines of the German Ophthalmological Society, which assessed the bilateral visual acuity and field using the visual impairment scale (VIS). ${ }^{6}$ Using specific tables based on visual acuity and visual field defects, we calculated the pre- and postoperative VIS scores, ranging from 0 (best) to 100 (worst). Before and after surgery, all patients underwent endocrinological evaluation. Serum pituitary hormone levels were measured, and an endocrinologist analyzed the results. In all patients, growth hormone $(\mathrm{GH})$, insulin-like growth factor-1, luteinizing hormone, follicle-stimulating hormone, estradiol or total testosterone, prolactin, free T4, thyroidstimulating hormone, adrenocorticotropic hormone, and serum cortisol levels were measured. In cases in which the 
TABLE 1. Clinical presentation and endocrinological status

\begin{tabular}{lccc}
\hline \multicolumn{1}{c}{ Variable } & Primary & Recurrent & Total \\
\hline No. of patients & 50 & 18 & 68 \\
\hline Presentation & & & \\
\hline Visual impairment & 42 & 2 & 44 \\
\hline Headache & 5 & 1 & 6 \\
\hline Altered consciousness & 3 & 0 & 3 \\
\hline Impaired cognition & 21 & 0 & 21 \\
\hline Seizure & 1 & 0 & 1 \\
\hline Amenorrhea & 2 & 0 & 2 \\
\hline Incidental & 1 & 0 & 1 \\
\hline Hydrocephalus & 7 & 0 & 7 \\
\hline Endocrinological status & & & \\
\hline No deficit & 13 & 4 & 17 \\
\hline GH deficiency & 3 & 0 & 3 \\
\hline Hypogonadism & 9 & 1 & 10 \\
\hline Panhypopituitarism & 25 & 13 & 38 \\
\hline
\end{tabular}

stalk was preserved, the combined pituitary function test was administered 4 months after surgery.

We used the Mann-Whitney U-test to compare tumor size between the groups. Fisher's exact test was used to compare the rate of GTR. ANOVA and Kruskal-Wallis tests were used to discriminate differences in changes in VIS score. To compare the clinical outcome according to the spatial relationship with the stalk, we used the chisquare test. Probability values were 2 -sided and significance was set at 0.05. SPSS software (version 23.0, IBM) was used in the statistical analyses.

\section{Surgical Procedures}

All procedures were performed using an endoscopic, endonasal, transplanum/tuberculum, or transsellar approach with an image-guided neuronavigation system. The details of the surgical procedures did not differ significantly from those described in the literature. ${ }^{4,8,14}$ After opening the dura, we first observed the relationship between the sellar and suprasellar structures, specifically, the relationship among the sellar and suprasellar structures, the tumor, and the diaphragma sellae. Dissecting the diaphragma from the dorsum sellae allowed for identification of the competency of the aperture and the exact location of the tumor relative to the diaphragma. After identifying the relationship between the tumor and surrounding structures, we dissected the tumor capsule from the neurovascular structures, such as the optic nerve tract and hypothalamus, without destroying the pia mater. The pituitary stalk was sacrificed if there was obvious tumor invasion. We reconstructed the skull base defect using various methods and applied a vascularized nasoseptal flap., ${ }^{1,3,9,12,13,16}$

\section{Results \\ Tumor Extent and Spatial Relationship to the Chiasm, Diaphragma Sellae, and Infundibulum}

We excluded 18 patients who had undergone prior surgery, because the relative surgical anatomy had been distorted during the previous operation. We categorized 50 consecutive cases of craniopharyngiomas according to the relative location of the tumor to the optic chiasm or infundibulum. ${ }^{14,30}$ Based on the preoperative MR images and intraoperative findings, 3 of the 50 tumors were classified as prechiasmatic and 47 as retrochiasmatic. When classified according to the relationship with the infundibulum, 8 tumors were preinfundibular, 36 tumors were transinfundibular, and the other 6 tumors were retroinfundibular. The correlation of the 2 classifications is presented in Table 2.

In addition, we classified the tumor into 2 categories based on the spatial relationship of the tumor and pituitary stalk. The intraoperative findings led us to classify the tumor into 2 subtypes: peripheral (Fig. 1) and central (Fig. 2). When the tumor was dissected from the stalk, the central type exhibited invasion of the central portion of the stalk. In contrast, tumor adhering on the surface of the pituitary stalk without invading the inner stalk was considered peripheral. The tumor invaded the center of the stalk in 36 cases and adhered to the surface of the stalk in 14 cases.

\section{Extent of Tumor}

GTR was achieved in 62 (91.1\%) of 68 patients. Preoperatively, we expected GTR to be possible in all cases. However, GTR could not be achieved in 6 cases because of severe adhesion between critical neurovascular structures and the tumor, as well as the cortical cuff, which interfered with visibility. For patients with primary tumors, 48 (96.0\%) of 50 tumors were completely removed; however, only $14(77.8 \%)$ of 18 recurrent tumors were totally resected. The GTR rate was significantly higher in the primary group than in the recurrent group $(\mathrm{p}=0.038)$. The relative anatomical relationship of the tumor to the surrounding structure did not affect the extent of tumor removal, as shown in Table 3.

STR was achieved in 2 of the 50 patients with primary tumors. These tumors had a retrochiasmatic growth pattern and were transinfundibular. The cystic portion of the tumors extended into the white matter of the frontal lobe,

TABLE 2. Tumor classification based on location in relation to the chiasm, diaphragma sellae, and infundibulum

\begin{tabular}{lcccc}
\hline \multicolumn{1}{c}{ Variable } & Preinfundibular & Transinfundibular & Retroinfundibular & Total \\
\hline Prechiasmatic & 2 & 0 & 1 & 3 \\
\hline Retrochiasmatic w/ intact diaphragma sellae & 6 & 24 & 2 & 32 \\
\hline Retrochiasmatic w/ incompetent diaphragma sellae & 0 & 12 & 3 & 15 \\
\hline Total & 8 & 36 & 6 & 50 \\
\hline
\end{tabular}

Values are numbers of tumors. 

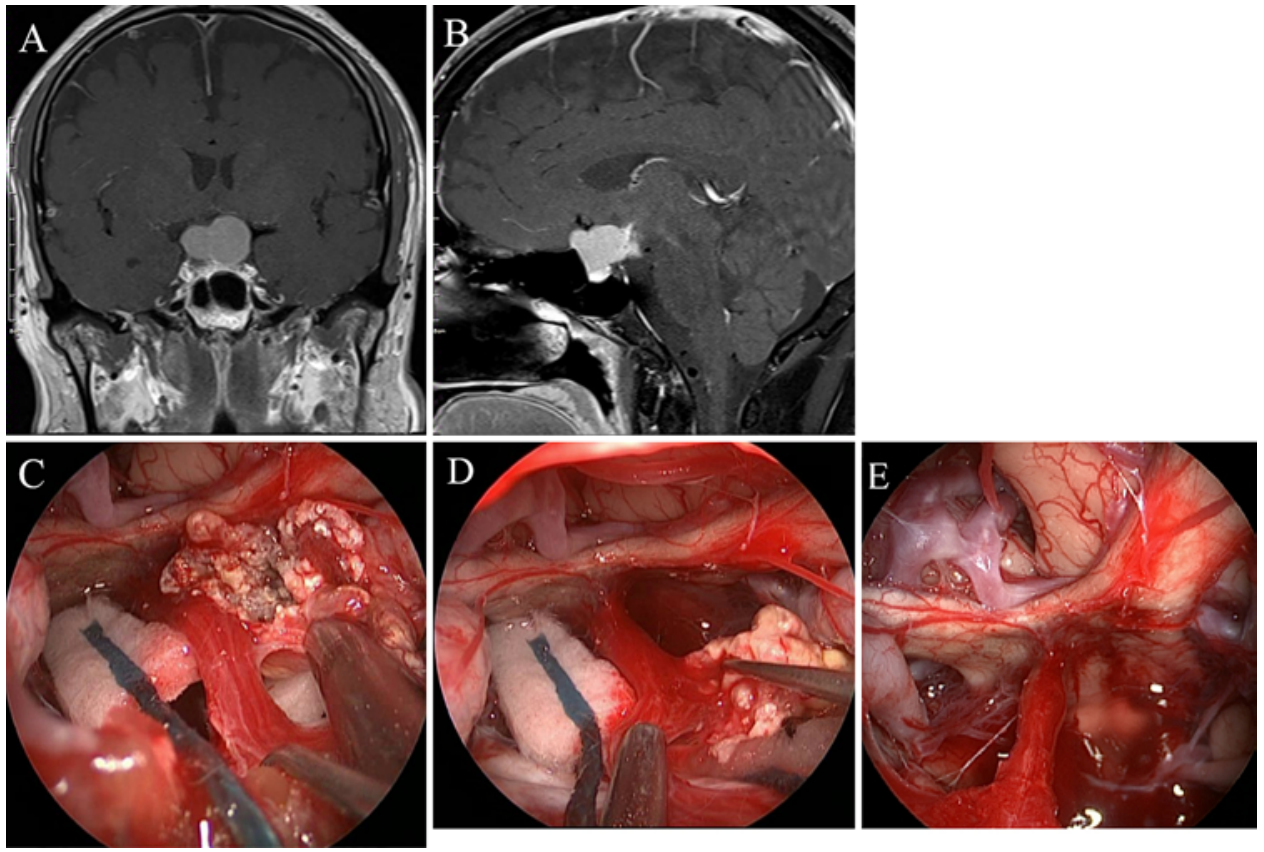

FIG. 1. Example of a peripheral-type craniopharyngioma. A and B: Coronal (A) and sagittal (B) MR images showing poor demarcation of the pituitary stalk. C and D: Intraoperative photographs showing that the tumor was attached to the surface of pituitary stalk and did not invade it. E: Intraoperative photograph showing that the pituitary stalk was completely preserved after tumor removal. Figure is available in color online only.

and therefore the cortical cuff of the frontal lobe prohibited GTR. In the recurrent group, STR was performed in 4 patients. In 3 of these 4 patients, the tumor adhered to the top of the basilar artery ( 1 case) and the ICA ( 2 cases).
GTR was limited in a patient who experienced recurrence because of a severe adhesive cystic lesion in the left hypothalamus. One patient who underwent STR was treated with upfront radiation therapy. Regular imaging and clini-
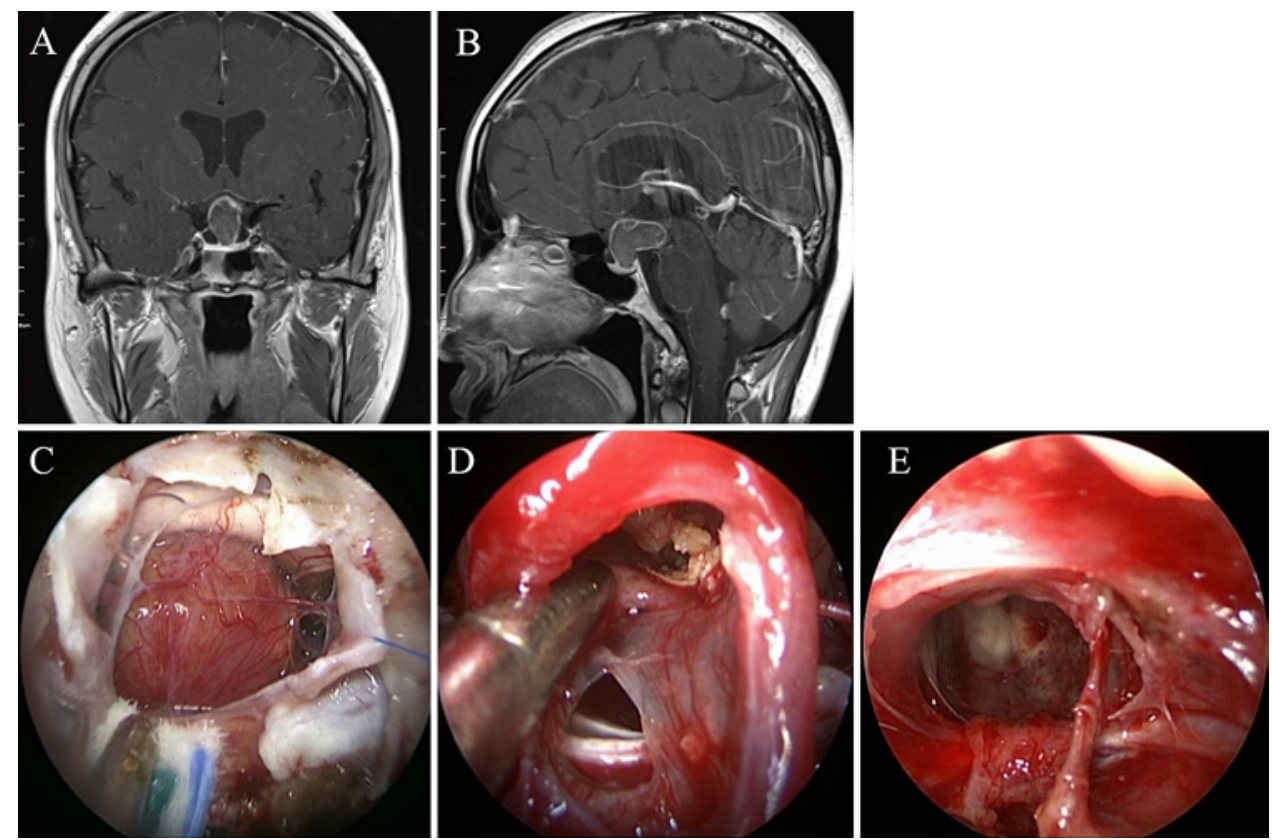

FIG. 2. Example of a central-type craniopharyngioma. A and B: Coronal (A) and sagittal (B) MR images showing enlargement of the pituitary stalk by the tumor. C: Intraoperative photograph obtained after dural incision, showing the stalk and optic chiasm. The stalk was enlarged and thinned by the tumor. D and E: Intraoperative photographs with $(D)$ and without $(E)$ surgical equipment, showing tumor dissection from the stalk, which covered the tumor surface after the incision on the site where the thinnest stalk tissue remained. Figure is available in color online only. 
TABLE 3. Surgical outcomes of patients with primary tumors in our study stratified by the different anatomical classification schemes

\begin{tabular}{|c|c|c|c|c|c|c|c|c|c|c|}
\hline \multirow[b]{2}{*}{ Anatomical Classification } & \multirow{2}{*}{$\begin{array}{l}\text { GTR } \\
(\%)\end{array}$} & \multicolumn{2}{|c|}{$\begin{array}{l}\text { Mean VIS } \\
\text { Score }\end{array}$} & \multicolumn{3}{|c|}{$\begin{array}{c}\text { Endocrinological } \\
\text { Change }\end{array}$} & \multicolumn{2}{|c|}{$\begin{array}{l}\text { Hypothalamic } \\
\text { Dysfunction }\end{array}$} & \multirow{2}{*}{$\begin{array}{c}\text { CSF } \\
\text { Leakage }\end{array}$} & \multirow[b]{2}{*}{ Infection } \\
\hline & & Preop & Postop & Improved & No Change & Deteriorated & Preop & Postop & & \\
\hline \multicolumn{11}{|l|}{ Wang et al., 2005} \\
\hline Prechiasmatic & $3 / 3(100)$ & 54.1 & 3.3 & 1 & 2 & 0 & 0 & 0 & 0 & 0 \\
\hline $\begin{array}{l}\text { Retrochiasmatic w/ intact } \\
\text { diaphragma sellae }\end{array}$ & $31 / 32(96.9)$ & 44.4 & 12.8 & 3 & 10 & 19 & 14 & 1 & 2 & 3 \\
\hline $\begin{array}{l}\text { Retrochiasmatic w/ incompetent } \\
\text { diaphragma sellae }\end{array}$ & $14 / 15(93.3)$ & 54.5 & 20.3 & 0 & 5 & 10 & 7 & 0 & 0 & 4 \\
\hline \multicolumn{11}{|l|}{ Kassam et al., $2008^{14}$} \\
\hline Preinfundibular & $8 / 8(100)$ & 42.2 & 0.5 & 4 & 4 & 0 & 1 & 0 & 0 & 0 \\
\hline Transinfundibular & $34 / 36(94.4)$ & 47.2 & 17.7 & 0 & 10 & 26 & 16 & 1 & 2 & 5 \\
\hline Retroinfundibular & $6 / 6(100)$ & 29.6 & 14.1 & 0 & 3 & 3 & 4 & 0 & 0 & 2 \\
\hline \multicolumn{11}{|l|}{ Present study } \\
\hline \multicolumn{11}{|l|}{ Pituitary stalk invasion } \\
\hline Central & $34 / 36(94.4)$ & 47.2 & 17.7 & 0 & 10 & 26 & 16 & 1 & 2 & 5 \\
\hline Peripheral & $14 / 14$ & 18 & 7.3 & 4 & 7 & 3 & 5 & 0 & 0 & 2 \\
\hline
\end{tabular}

Values are number of patients (\%) unless otherwise indicated.

cal follow-up were recommended in 5 patients with small tumor capsules (1-1.5 $\mathrm{mm}$ ), which were invisible on MRI.

The overall mean tumor size was $2.5 \mathrm{~cm}(3.1 \mathrm{~cm}$ [range $1.2-7.0 \mathrm{~cm}$ ] in the primary group and $1.9 \mathrm{~cm}$ [range $1.0-$ $3.1 \mathrm{~cm}]$ in the recurrent group). Tumor size did not significantly affect GTR $(p=0.676)$.

\section{Ophthalmological Outcome}

Vision based on objective examination improved after surgery in $44(64.7 \%)$ of 68 patients, remained the same in $18(26.5 \%)$, and deteriorated in the remaining 6 patients. The mean pre- and postoperative VIS scores in 68 patients were 40.8 and 22.1 , respectively. Thirty-eight $(86.4 \%)$ of 44 patients with preoperative subjective visual disturbance experienced visual improvement and $2(4.5 \%)$ showed no change in vision; the remaining 4 patients experienced vision deterioration. The pre- and postoperative VIS scores in patients with subjective visual disturbance were 59.3 and 23.3, respectively. Twenty-four of the 68 patients did not complain of visual disturbance. Improved vision was reported in $6(25.0 \%)$ of 24 patients without subjective visual symptoms, and 18 of these patients showed no change in vision after surgery.

None of the 3 classification systems were significantly associated with visual improvement $(\mathrm{p}=0.482, \mathrm{p}=0.480$, and $p=0.228$ for the classifications of Wang et al. ${ }^{30}$ Kassam et al., ${ }^{14}$ and the present study, respectively). All subgroups in the 3 classifications showed an improvement in VIS score after surgery, as shown in Table 3.

Four patients (5.9\%) had deterioration in total VIS score after surgery. Two patients in the primary group and 2 patients in the recurrent group had preoperative visual disturbance. In the primary group, 1 patient with preoperative visual disturbance experienced progressively deteriorating visual acuity in 1 eye at 6 months after surgery, despite improvements in both eyes during the immediate postoperative period. Postoperative bilateral temporal hemianopia occurred in another patient. In this case, the stalk resection site was very close to the chiasm; therefore, we speculated that the procedure might influence the result. Both patients had a retrochiasmatic tumor with an intact diaphragm, and the pituitary stalk was sacrificed just below the optic chiasm because of tumor invasion. In the recurrent group, 2 patients had tumors that severely adhered to the optic nerve. Tumor dissection was difficult because of these adhesions. Therefore, the overall postoperative vision deterioration rate after surgery was 5.9\% (4 of 68 patients). However, no blindness occurred after surgery.

\section{Endocrinological Outcome}

Preoperative endocrinological evaluation revealed anterior pituitary insufficiency in 51 patients ( 37 and 14 patients in the primary and recurrent tumor groups, respectively) to various degrees and diabetes insipidus in 1 patient (1.5\%). Postoperatively, 55 patients had panhypopituitarism (40 and 15 in the primary and recurrent groups, respectively), 12 patients had normal endocrine function (9 and 3 in the primary and recurrent groups, respectively), and 1 patient exhibited GH deficiency. Forty-four patients (64.7\%) were diagnosed with diabetes insipidus after surgery (43 cases of new-onset diabetes insipidus and 1 patient with preoperative diabetes insipidus). Endocrinological function improved in only 4 patients (7.8\%) and deteriorated in 32 of 68 patients $(45.6 \%)$.

In the primary group, the endocrinological status improved in $4(10.8 \%)$ of 37 and deteriorated in $29(58.0 \%)$ of 50 patients. Of 9 patients with normal endocrine function after surgery, 8 patients had preinfundibular-type tumors and 1 patient had a retroinfundibular-type tumor. All of these tumors adhered to the surface of the stalk only. Similarly, of the 40 patients with postoperative panhypopituitarism, 35 harbored transinfundibular and 5 harbored retroinfundibular tumors. The pituitary gland and stalk were preserved in $23(46 \%)$ of 50 patients with primary tumors, 
but endocrinological function was preserved in only 10 (43.4\%) of these patients. Transinfundibular tumors invade the central portion of the pituitary stalk, and at our institution the stalk is usually removed in such cases. Among the 36 patients with transinfundibular tumors, the stalk was preserved in $10(27.8 \%)$. None of the patients in the recurrent group had endocrinological improvement, and deterioration after surgery was noted in 3 of 18 patients (16.7\%).

Body mass index (BMI) was calculated pre- and postoperatively in all patients. The pre- and postoperative mean BMIs were 25.2 and $26.1 \mathrm{~kg} / \mathrm{m}^{2}$, respectively. The pre- and postoperative mean BMIs of the 55 patients with postoperative hypopituitarism were 25.5 and $26.4 \mathrm{~kg} / \mathrm{m}^{2}$, respectively. In contrast, the BMIs of the 13 patients without postoperative endocrinological deficits were 23.9 and $25.3 \mathrm{~kg} / \mathrm{m}^{2}$, respectively. Sixteen patients exhibited a $>9 \%$ BMI increase after surgery, and 14 of these patients required glucocorticoid replacement due to hypopituitarism. There was no deterioration in cognitive function in any of these patients.

\section{Cognitive Dysfunction and Hydrocephalus}

Cognitive dysfunction was noted in 22 of 68 patients (21 patients with primary tumors and 1 with recurrence) before surgery and resolved completely in 20 patients $(90.9 \%)$ after surgery. All 21 primary tumors in the patients with cognitive dysfunction were retrochiasmatic and included 1 preinfundibular, 16 transinfundibular, and 4 retroinfundibular tumors. According to our classification, 16 tumors were central and 5 were peripheral. Regarding cognitive dysfunction and the tumor's location relative to the stalk, the difference in the cognitive dysfunction rate was not statistically significant between central and peripheral tumors $(\mathrm{p}=0.574)$.

In the recurrent group, 2 patients exhibited cognitive dysfunction after surgery. Compared with their preoperative status, cognitive dysfunction improved; however, these patients did not return to an active social life or carry on active normal daily living by themselves. Therefore, postoperative cognitive dysfunction remained in $3(4.4 \%)$ of the 68 study patients after surgery, 1 primary tumor patient with preexisting cognitive dysfunction and 2 recurrent tumor patients, 1 with preexisting and 1 with new-onset cognitive dysfunction.

Preoperative obstructive hydrocephalus was observed in 7 cases and resolved in all cases after surgery without additional CSF diversion procedures. The foramen of Monro was obstructed by tumor in 5 cases, and obstruction at the outlet of the third ventricle was the cause of hydrocephalus in 2 cases. The direction of tumor growth seems to determine the obstruction point of preoperative hydrocephalus.

\section{Postoperative Complications and Recurrence}

The most common complication was meningitis, occurring in 12 patients ( 7 patients with primary tumors and 5 with recurrence). No bacterial or fungal infection was identified in 11 cases; fungal ventriculitis occurred in 1 recurrent case. Two patients underwent revision surgery because CSF leakage was observed on endonasal examination performed on postoperative Day 2. Ten patients without CSF leakage had a similar clinical course. All patients exhibited typical meningitis symptoms, such as headache, fever, meningeal irritation sign 2-3 weeks after surgery. Mild leukocytosis and low glucose levels were observed on examination of the CSF, and empirical antibiotics were administered. At the same time, there was no CSF leakage when endonasal examination was performed. No CSF leakage was seen on repeated endoscopic examinations performed at 3- to 4-day intervals. Bacterial growth was not seen in any case according to results of culture studies. Thus, we diagnosed these cases as aseptic meningitis and speculated that the main cause of meningitis was chemical irritation caused by tumor content. The difference in infection rate was not statistically significant between the groups.

CSF leakage occurred in $2(2.9 \%)$ of the 68 patients and was repaired successfully through EEA. These patients underwent gasket-seal reconstruction with artificial dura (Surgisis) and artificial bony substitute (Medpore) covered by a nasoseptal flap. Insufficient coverage of the flap on the bone defect site was found in one patient and broken reconstruction material was found in the other patient. After encountering 2 gasket seal technique failures, we began using the button graft technique of fascia or hydroxyapatite cement paste, followed by the on-layer nasoseptal flap. There were no major vessel injuries or new-onset cranial nerve palsies after surgery, and there were no deaths in this study.

There were 2 tumor recurrences during the follow-up period. Both recurrences were in the primary group and were discovered 13 months and 58 months after GTR. The patient who exhibited recurrence 13 months after surgery was treated with Gamma Knife surgery due to the small tumor size and the its location at the hypothalamus. Another patient who exhibited recurrence at the suprasellar area 58 months after surgery underwent revision endonasal surgery, and the tumor was removed totally.

\section{Discussion}

There are several anatomical classifications of craniopharyngioma based on the relationship of the tumor to anatomical structures..$^{10,14,21-23,25}$ Therefore, different surgical approaches are recommended depending on the extent of the tumor and its relative location to adjacent structures. ${ }^{7,19}$ These different classifications are also related to surgical outcomes, such as the possible extent of tumor removal and postoperative complications. For example, endocrinological dysfunction of the pituitary gland is more prevalent in subdiaphragmatic craniopharyngiomas, and a greater frequency of hypothalamic dysfunction has been reported for craniopharyngiomas invading the third ventricle. ${ }^{19,24}$

Our group previously proposed the hypothesis that tumor origin relative to the optic chiasm and diaphragma sellae determines the craniopharyngioma growth pattern and that various surgical features and the adhesion pattern differ accordingly, based on transcranial observations. ${ }^{30}$ Because of the recent evolution of the EEA, the anatomical structures can be seen in more detail than in the intracranial approach and microscopic transsphenoidal approach, and thus more classifications of craniopharyngioma have been introduced. ${ }^{21}$ Kassam et al. suggested a classification system using a spatial relationship between the infundibu- 
lum and tumor and reported clinical outcomes according to the classification. ${ }^{14}$ We categorized craniopharyngioma and described clinical outcomes on the basis of intraoperative findings.

As EEA is widely used as a surgical strategy for craniopharyngioma, several groups have reported outcomes for craniopharyngioma surgery using this technique. The rate of GTR has been reported to vary from $28.6 \%$ to $77.8 \%{ }^{2,11,17,18,32}$ The detailed surgical view of the surrounding neurovascular structures provided by endoscopy allows for total resection of the tumor. In this study, the rate of GTR was $91.1 \%$ (62 of 68 patients), and there were no significant differences between the groups when using any of the classification systems.

Previously, GTR of craniopharyngioma was deemed difficult because of its greater perioperative complication rate; therefore, adjunctive radiotherapy after STR has been preferred by some investigators.,19,20,26 Studies comparing the rate of disease control between STR followed by adjuvant radiotherapy and GTR reported similar disease control rates, with a lower complication rate for the former. ${ }^{28,31,33}$ However, long-term complications after radiotherapy, such as cognitive dysfunction, hypopituitarism, and secondary tumor, cannot be neglected. ${ }^{15}$ Surgery is the therapy of choice in cases of recurrence after radiotherapy. However, as shown in our previous report, surgery is difficult after STR because of the severe adhesions..$^{30}$ Consequently, GTR has the advantage of a low recurrence rate and thus no need for adjuvant therapy, such as radiotherapy.

Several studies have reported ophthalmological outcomes of patients after undergoing EEA for craniopharyngioma. ${ }^{1,17,18}$ These studies revealed that $76.3 \%$ to $85.7 \%$ of patients who had visual disturbance before surgery experienced improved vision postoperatively.

In our study, 43 (97\%) of 44 patients who had visual disturbance showed improvement in VIS score, and the visual improvement was not related to the anatomical subtypes of tumors, as shown in Table 3. Because craniopharyngioma arose from the pituitary stalk, the anatomy between the optic nerve and tumor could be better visualized with an EEA than a transcranial approach. Moreover, microdissection of the hypophyseal artery, which is located at the bottom of the optic nerve, can be achieved under direct surgical view. Therefore, we were able to dissect and save the superior hypophyseal artery in all cases during tumor resection. Direct decompression of the optic chiasm and preservation of the superior hypophyseal artery could cause the high rate of visual improvement.

According to the literature, endocrinological dysfunction after surgery for craniopharyngioma seems inevitable. . $^{1,2,8,17,18} \mathrm{~A}$ recent case series in which patients underwent the endoscopic skull base approach for craniopharyngioma reported the postoperative panhypopituitarism rate as ranging from $18 \%$ to $67 \%$ based on the extent of the resection. In the study by Koutourousiou et al., the goal of resection was symptom relief and the avoidance of surgery-related morbidity. They adopted STR if GTR was considered dangerous and reported a $42 \%$ rate of endocrinological worsening. ${ }^{17}$ In this study, we also attempted to preserve the stalk, even if it exhibited tumor involvement in its core. However, in those cases, pituitary function was not maintained in $70 \%$ despite stalk preservation. As a result, the $58 \%$ endocrinological deterioration rate reported here is higher than that in other reports.

The spatial relationship between the stalk and the tumor is crucial for postoperative endocrine function. Applying the classification established by Kassam et al. ${ }^{14}$ to our primary tumor group, in terms of endocrinological tests, transinfundibular and pre-/retroinfundibular tumors were associated with deterioration in $72.2 \%$ and $21.4 \%$ of patients, respectively, after surgery. The authors also categorized craniopharyngioma on the basis of intraoperative tumor invasion into the pituitary stalk. Peripheral tumors could be dissected from the stalk without disruption of the arachnoid membrane, thus salvaging pituitary function. The difference in the rate of endocrinological deterioration was statistically significant between the central and peripheral groups ( $\mathrm{p}=0.001$; Table 3$)$. The previous 2 classification schemes are very useful in determining surgical approach but do not seem to reflect the surgical outcome, especially from an endocrinological point of view. ${ }^{14,30}$ The relationship between the tumor and stalk is crucial in determining the clinical status after surgery.

Several studies have reported on cognitive function after EEA. Memory disturbance, postoperative employment status, and BMI have been used to evaluate cognitive function. . $^{2,18,27}$ We excluded BMI from criteria, as hormone replacement therapy, especially corticosteroid therapy, could influence BMI after surgery. Preoperative cognitive dysfunction was improved in $90.9 \%$, and new cognitive dysfunction occurred in $1.5 \%$ of patients after surgery. Without regard to the anatomical classifications, cognitive dysfunction was improved after surgery. Because cognitive dysfunction occurred frequently after GTR performed via the transcranial approach, previous studies reported a low rate of GTR after the transcranial approach. However, cognitive dysfunction improved after gentle microdissection under direct view with an EEA. We were able to observe the tumor-hypothalamus interface directly through endoscopic visualization; therefore, tumor dissection could be performed without damaging the hypothalamus. However, if there were severe adhesion between the tumor and hypothalamus, STR would preserve quality of life.

A CSF leakage rate ranging from $0 \%$ to $58 \%$ has been reported after craniopharyngioma resection via EEA. ${ }^{1,2,8}$, ${ }_{17,18}$ The development of the skull base reconstruction technique and the introduction of the vascularized septal flap significantly reduced the rate of CSF leakage. ${ }^{1,9,13,16}$ Overall, the CSF leakage rate of our group was $2.9 \%$, and it was lower than that in other groups. ${ }^{1,17,18}$ However, the rate of meningitis was higher than that in these groups, separate from the CSF leakage rate. In our primary group, postoperative meningitis was more prevalent in patients with retrochiasmatic tumors than in those with prechiasmatic tumors. Prechiasmatic tumors were located under the diaphragma sellae; therefore, no CSF leakage occurred in any of these cases. However, there was high-flow CSF leakage due to the opening of the third ventricle in the retrochiasmatic group. However, with the exception of 1 patient with fungal ventriculitis, no bacterial infection was seen in patients with meningitis. 


\section{Conclusions}

Advancements in EEA devices and techniques have changed the surgical strategy for craniopharyngioma from the transcranial and microscopic transsphenoidal approaches to EEA. EEA, which could extend through the planum and tuberculum sellae, is the ideal surgical approach in most cases. The direct and clear visualization of the interface between the tumor and surrounding critical neural structures, such as the optic apparatus and the hypothalamus, provides safe and adequate tumor resection. Excellent surgical outcomes and acceptable morbidity have been achieved with EEA.

We have demonstrated that extent of tumor removal and improvement in vision are dependent on whether the tumor was primary. When the tumor was resected gross totally, endocrinological outcome was determined by whether the tumor invaded into the center of the pituitary stalk. Outcomes of postoperative cognitive dysfunction, complication, and recurrence were favorable and were not influenced by pituitary involvement.

\section{Acknowledgments}

This study was supported by a grant (HI16C-1111-020016) to Yong Hwy Kim from the National Research Foundation of Korea.

\section{References}

1. Campbell PG, McGettigan B, Luginbuhl A, Yadla S, Rosen M, Evans JJ: Endocrinological and ophthalmological consequences of an initial endonasal endoscopic approach for resection of craniopharyngiomas. Neurosurg Focus 28(4): E8, 2010

2. Cavallo LM, Frank G, Cappabianca P, Solari D, Mazzatenta D, Villa A, et al: The endoscopic endonasal approach for the management of craniopharyngiomas: a series of 103 patients. J Neurosurg 121:100-113, 2014

3. Cavallo LM, Messina A, Esposito F, de Divitiis O, Dal Fabbro M, de Divitiis E, et al: Skull base reconstruction in the extended endoscopic transsphenoidal approach for suprasellar lesions. J Neurosurg 107:713-720, 2007

4. de Divitiis E, Cavallo LM, Cappabianca P, Esposito F: Extended endoscopic endonasal transsphenoidal approach for the removal of suprasellar tumors: Part 2. Neurosurgery 60:46-59, 2007

5. Elliott RE, Sands SA, Strom RG, Wisoff JH: Craniopharyngioma Clinical Status Scale: a standardized metric of preoperative function and posttreatment outcome. Neurosurg Focus 28(4):E2, 2010

6. Fahlbusch R, Schott W: Pterional surgery of suprasellar meningiomas of the tuberculum sellae and planum sphenoidale: surgical results with special consideration of ophthalmological and endocrinological results. J Neurosurg 96:235-243, 2002

7. Fernandez-Miranda JC, Gardner PA, Snyderman CH, Devaney KO, Strojan P, Suárez C, et al: Craniopharyngioma: a pathologic, clinical, and surgical review. Head Neck 34:1036-1044, 2012

8. Frank G, Pasquini E, Doglietto F, Mazzatenta D, Sciarretta V, Farneti G, et al: The endoscopic extended transsphenoidal approach for craniopharyngiomas. Neurosurgery 59 (1 Suppl 1):ONS75-ONS83, 2006

9. Garcia-Navarro V, Anand VK, Schwartz TH: Gasket seal closure for extended endonasal endoscopic skull base sur- gery: efficacy in a large case series. World Neurosurg 80:563-568, 2013

10. Hoffman HJ: Surgical management of craniopharyngioma. Pediatr Neurosurg 21 (Suppl 1):44-49, 1994

11. Jane JA Jr, Kiehna E, Payne SC, Early SV, Laws ER Jr: Early outcomes of endoscopic transsphenoidal surgery for adult craniopharyngiomas. Neurosurg Focus 28(4):E9, 2010

12. Kassam A, Carrau RL, Snyderman CH, Gardner P, Mintz A: Evolution of reconstructive techniques following endoscopic expanded endonasal approaches. Neurosurg Focus 19(1):E8, 2005

13. Kassam AB, Thomas A, Carrau RL, Snyderman CH, Vescan A, Prevedello D, et al: Endoscopic reconstruction of the cranial base using a pedicled nasoseptal flap. Neurosurgery 63 (1 Suppl 1):ONS44-ONS53, 2008

14. Kassam AB, Gardner PA, Snyderman CH, Carrau RL, Mintz AH, Prevedello DM: Expanded endonasal approach, a fully endoscopic transnasal approach for the resection of midline suprasellar craniopharyngiomas: a new classification based on the infundibulum. J Neurosurg 108:715-728, 2008

15. Kiehna EN, Merchant TE: Radiation therapy for pediatric craniopharyngioma. Neurosurg Focus 28(4):E10, 2010

16. Kitano M, Taneda M: Icing and multilayering technique of injectable hydroxyapatite cement paste for cranial base reconstruction after transsphenoidal surgery: technical note. Neurosurgery 61 (3 Suppl):E53-E54, 2007

17. Koutourousiou M, Gardner PA, Fernandez-Miranda JC, Tyler-Kabara EC, Wang EW, Snyderman CH: Endoscopic endonasal surgery for craniopharyngiomas: surgical outcome in 64 patients. J Neurosurg 119:1194-1207, 2013

18. Leng LZ, Greenfield JP, Souweidane MM, Anand VK, Schwartz TH: Endoscopic, endonasal resection of craniopharyngiomas: analysis of outcome including extent of resection, cerebrospinal fluid leak, return to preoperative productivity, and body mass index. Neurosurgery 70:110-124, 2012

19. Mortini P, Losa M, Pozzobon G, Barzaghi R, Riva M, Acerno $S$, et al: Neurosurgical treatment of craniopharyngioma in adults and children: early and long-term results in a large case series. J Neurosurg 114:1350-1359, 2011

20. Müller HL: Consequences of craniopharyngioma surgery in children. J Clin Endocrinol Metab 96:1981-1991, 2011

21. Pascual JM, Carrasco R, Prieto R, Gonzalez-Llanos F, Alvarez F, Roda JM: Craniopharyngioma classification. J Neurosurg 109:1180-1183, 2008

22. Pascual JM, Prieto R, Carrasco R: Infundibulo-tuberal or not strictly intraventricular craniopharyngioma: evidence for a major topographical category. Acta Neurochir (Wien) 153:2403-2426, 2011

23. Qi S, Lu Y, Pan J, Zhang X, Long H, Fan J: Anatomic relations of the arachnoidea around the pituitary stalk: relevance for surgical removal of craniopharyngiomas. Acta Neurochir (Wien) 153:785-796, 2011

24. Qi S, Pan J, Lu Y, Gao F, Cao Y, Peng J, et al: The impact of the site of origin and rate of tumour growth on clinical outcome in children with craniopharyngiomas. Clin Endocrinol (Oxf) 76:103-110, 2012

25. Śteňo J, Malácek M, Bízik I: Tumor-third ventricular relationships in supradiaphragmatic craniopharyngiomas: correlation of morphological, magnetic resonance imaging, and operative findings. Neurosurgery 54:1051-1060, 2004

26. Sughrue ME, Yang I, Kane AJ, Fang S, Clark AJ, Aranda D, et al: Endocrinologic, neurologic, and visual morbidity after treatment for craniopharyngioma. J Neurooncol 101:463476, 2011

27. Van Gompel JJ, Nippoldt TB, Higgins DM, Meyer FB: Magnetic resonance imaging-graded hypothalamic compression in surgically treated adult craniopharyngiomas determining postoperative obesity. Neurosurg Focus 28(4):E3, 2010 
28. Veeravagu A, Lee M, Jiang B, Chang SD: The role of radiosurgery in the treatment of craniopharyngiomas. Neurosurg Focus 28(4):E11, 2010

29. Wang KC, Kim SK, Choe G, Chi JG, Cho BK: Growth patterns of craniopharyngioma in children: role of the diaphragm sellae and its surgical implication. Surg Neurol 57:25-33, 2002

30. Wang KC, Hong SH, Kim SK, Cho BK: Origin of craniopharyngiomas: implication on the growth pattern. Childs Nerv Syst 21:628-634, 2005

31. Winkfield KM, Tsai HK, Yao X, Larson E, Neuberg D, Pomeroy SL, et al: Long-term clinical outcomes following treatment of childhood craniopharyngioma. Pediatr Blood Cancer 56:1120-1126, 2011

32. Yamada S, Fukuhara N, Oyama K, Takeshita A, Takeuchi Y, Ito J, et al: Surgical outcome in 90 patients with craniopharyngioma: an evaluation of transsphenoidal surgery. World Neurosurg 74:320-330, 2010

33. Yang I, Sughrue ME, Rutkowski MJ, Kaur R, Ivan ME, Aranda D, et al: Craniopharyngioma: a comparison of tumor control with various treatment strategies. Neurosurg Focus 28(4):E5, 2010

\section{Disclosures}

The authors report no conflict of interest concerning the materials or methods used in this study or the findings specified in this paper.

\section{Author Contributions}

Conception and design: YH Kim, Park, Wang, DG Kim. Acquisition of data: YH Kim, Dho, Se, Han, JH Kim. Analysis and interpretation of data: YH Kim, Dho, JH Kim. Drafting the article: Dho. Critically revising the article: Wang.

\section{Correspondence}

Yong Hwy Kim, Department of Neurosurgery, Seoul National University Hospital, Daehak-ro 101, Jongno-gu, Seoul 110-744, Republic of Korea. email: kimyh96@snu.ac.kr. 